\title{
Moving towards global satellite based products for monitoring of inland and coastal waters. Regional examples from Europe and South America
}

\author{
E. Spyrakos ${ }^{1}$, P. Hunter ${ }^{1}$, S. Simis ${ }^{2}$, C. Neil ${ }^{1}$, C. Riddick ${ }^{1}$, S. Wang ${ }^{1}$, A. Varley ${ }^{1}$, M. Blake ${ }^{1}$, S. Groom ${ }^{2}$, J Torres Palenzuela ${ }^{3}$, L. \\ Vilas Gonzalez $^{3}$, C. Cardenas ${ }^{4}$, M. Frangopulos ${ }^{4}$, X. Aguilar Vega ${ }^{4}$ J. L. Iriarte ${ }^{5}$, A. Tyler ${ }^{1}$
}

\author{
${ }^{1}$ Dept. of Biological and Environmental Sciences, Natural Sciences Faculty, University of Stirling, Stirling, FK9 4LA, UK- \\ (evangelos.spyrakos@stir.ac.uk, peter.d.hunter@stir.ac.uk, claire.neil@stir.ac.uk, caitlin.riddick1@stir.ac.uk, \\ shenglei.wang@stir.ac.uk, a.1.varley@stir.ac.uk,matthew.blake@stir.ac.uk, a.n.tyler@stir.ac.uk) \\ ${ }^{2}$ Plymouth Marine Laboratory, Plymouth PL1 3DH, United Kingdom (stsi@pml.ac.uk, sbg@pml.ac.uk) \\ ${ }^{3}$ Remote Sensing and GIS Laboratory, Department of Applied Physics, Sciences Faculty, University of Vigo, Campus Lagoas \\ Marcosende, 36310 Vigo, Spain (jesu@uvigo.es, luisgv@uvigo.es) \\ ${ }^{4}$ Centro de Investigación Gaia-Antártica, Universidad de Magallanes, Avenida Bulnes 01855, Casilla 113-D, Punta Arenas, Chile \\ (carlos.cardenas@umag.cl,maxfrangopulos@gmail.com, xaguilar@umag.cl) \\ ${ }^{5}$ Instituto de Acuicultura, Universidad Austral de Chile, Los Pinos s/n Balneario Pelluco, Puerto Montt (jiriarte@uach.cl)
}

KEY WORDS: Remote sensing, coastal waters, lakes, global products, Patagonian fjords

\begin{abstract}
:
Surface waters are a fundamental resource. They fulfil key function in global biogeochemical cycles and are core to our water, food and energy security. The rapidly increasing rate of data collection from different Earth observation (EO) missions suitable for observing water bodies has promoted satellite remote sensing (RS) as a more widely recognised source of information on a number of indicators of water quality and ecosystem condition at local and global scales. In parallel, advances in optical sensors support new and more detailed characterisation of the Earth surface and could lead to innovative EO-based products. Nonetheless, RS of water colour of inland and coastal systems, especially in larger scales and over long-term time series, faces unique challenges. This study provides an overview of the challenges and solutions of developing a global observation platform, including the diverse and complex optical properties of inland waters and guided algorithm selection procedure required to deliver reliable data. The development and validation of a global satellite data processing chain (Calimnos) has been supported by access to an extensive in situ data from more than thirty partners around the world that are now held in the LIMNADES community-owned database. This approach has resulted in a step-change in our ability to produce regional and global water quality products for optically complex waters. Local examples of the data outputs will be explored and the opportunities in how these data can be embedded within local and national monitoring schemes to facilitate better management of water will be discussed.
\end{abstract}

\section{MANUSCRIPT}

\subsection{Introduction}

The world's aquatic ecosystems are vital components of the global biosphere, yet are vulnerable to climate and other humaninduced change. The mounting and conflicting pressures from the number of users and uses, coupled with population growth, industrialisation, land use intensification and climate change bring into focus the urgent need for the sustainable management of these systems. There is an obvious need for appropriate monitoring and management methods in order to protect these systems from deterioration and ensure the provision of ecosystem goods and services. A recent study based on Earth observation (EO) data estimates that there are around 117 million water bodies larger than $0.002 \mathrm{~km}^{2}$ on the Earth (Verpoorter et al., 2014). This large number restricts systematic monitoring and study through conventional in-situ methods.

The increasing availability of free-to-access satellite data from current missions has radically transformed the approaches to monitor and sustainably manage coastal, inland and transitional systems and has stimulated rapid growth in the development of downstream services. In parallel, advances in optical sensors support new and more detailed characterisation of the Earth surface and can lead to innovative and higher-level EO-based products. Nonetheless, remote sensing (RS) of water colour of inland and coastal systems, especially in larger scales and over long-term time series, faces unique challenges such as temporally and spatially variable in-water optical conditions, continentality in atmospheric characteristics, complex shorelines and inconsistencies in satellite and vicarious calibration data collection. The diverse and complex optical properties of inland and coastal waters results in often markedly variable algorithm performance between water types with different optical properties. In spite of these and other challenges, there is an urgent need for reliable remote sensing techniques to operationally monitor these important aquatic resources - a need that is well understood and agreed upon by the research community and operational environmental monitoring agencies worldwide. This conference paper will describe the challenges and solutions of developing global observation platforms, including the diverse and complex optical properties of inland and coastal waters and guided algorithm selection procedure required to deliver reliable data (NERC GloboLakes project). This talk will also summarise our research and activities in developing and validating innovative and higher-level EO-based products (e.g. Primary Production (PP), Phytoplankton Size Classes (PSC) and Harmful Algal Blooms (HABs)) over these waters (H2020 CoastObs project). Examples of the data outputs will be explored and the opportunities in how these data can be embedded within local and national monitoring schemes to facilitate better management of water and sanitation (H2020 EOMORES, H2020 CoastObs, GCRF/EPSRC) will be discussed, primarily as a mechanism to drive change via community action and informed governance. Finally, we will also present preliminary results from the intense biogeoptical characterisation and validation activities in Chile (Conicyt MEC) during 2019. We will provide new information on the bio-optics in these systems, 
which is important for optical models and remote sensing of these systems.

\subsection{The need for global high quality in-situ data}

The availability of high quality bio-optical datasets (e.g. inherent optical properties (IOPs), radiometric quantities and inwater constituent concentrations) is fundamental to radiative transfer studies and RS applications. They can also help us to answer the following question

- What is the scale of variation in IOPs and their mass specific representation?

-What are the functional relationships for parameterisation of biogeochemical variables in terms of optical properties?

This knowledge is considered crucial for the interpretation of remote sensing signal and thus the development of more accurate retrieval algorithms. In this context, satellite validation and calibration activities such as those linked to the ESA Copernicus Sentinel-2 and -3 missions and for other satellite missions both past and present (e.g. ESA MERIS, NASA SeaWiFS, MODIS) rely on high quality in situ data. However, these data for inland and coastal waters are scarce. Harmonized repositories of collated datasets could provide an arena to consider best practice and where appropriate standardisation of operating procedures to enable a convergence in data quality and compatibility.

LIMNADES (Fig. 1) provides a centralized repository for measurements of IOPs, radiometric quantities and in-water constituent concentrations dedicated to inland and near-shore waters. There are approximately 39794 data measurements taken from 3547 stations that are available either through request or download from the LIMNADES database at the current time (https://limnades.stir.ac.uk). Measurements stretch back nearly 30 years with most being recorded between 2000 and the current time. The hope is to further grow the database into the future and fill in any gaps.

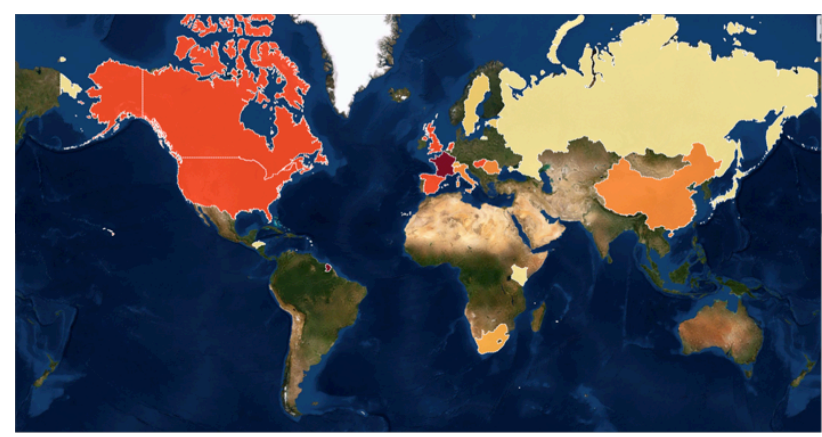

Figure 1. Interactive map showing the spatial distribution of the in-situ data available in LIMNADES (https://limnades.stir.ac.uk/Limnades_login/Statistics/Stats_boar d.php).

Concentrations of biogeochemical parameters in our dataset (more than 300 water bodies from very clear waters in alpine lakes to hypereutrophic lakes Kenya and very turbid transitional systems) spanned over several orders of magnitude and for some of these parameters data that will be presented in this talk constitute the widest ranges ever reported in bio-optical studies. More importantly, this database helped as identify some gaps such as the lack of backscattering scattering data, the representation and bias towards higher chlorophyll a (Chla) and phycocyanin (PC) values associated with increased sampling effort for PC in eutrophic systems and during cyanobacteria blooms.

\subsection{Global water quality products}

\subsubsection{Optical water types (OWT) Variability}

Another question that stands is what is the global variability in optical water types in inland and coastal waters. A good understanding of the OWT variability is considered crucial for the interpretation of RS signal and thus the development of more accurate retrieval algorithms. Spyrakos et al., (2018) introduced a novel approach for clustering in-situ radiometric data using functional data analysis. They identified 13 different OWT in inland waters and 9 OWT in coastal water. This typification provided a valuable framework for the development of a globally applicable EO scheme.

The definition of the clusters developed in that work was based on hyperspectral remote sensing reflectance $\operatorname{Rrs}(\lambda)$ but these can be resampled to any sensor spectral resolution to assess their capability to differentiate the suggested clusters. Different strategies may be used to accomplish the cluster assignment of satellite-derived spectra, but we chose to compile an example adopting an approach described in Moore et al. (2014) that has already been implemented in the ESA OceanColour-CCI project.

Briefly, the class membership of an input spectrum is evaluated using squared Mahalanobis distance and cumulative chi-squared distribution. Covariance matrices and cluster means were calculated on the in situ $\operatorname{Rrs}(\lambda)$ data at MERIS bands recreated using the sensor's spectral response functions. All spectra were standardised by dividing by the integral, which always led to substantial improvement in cluster membership. For the 13 clusters identified in the inland water dataset the agreement was 0.85. However, in some cases the differences in class membership between the top and second ranking cluster were negligible.

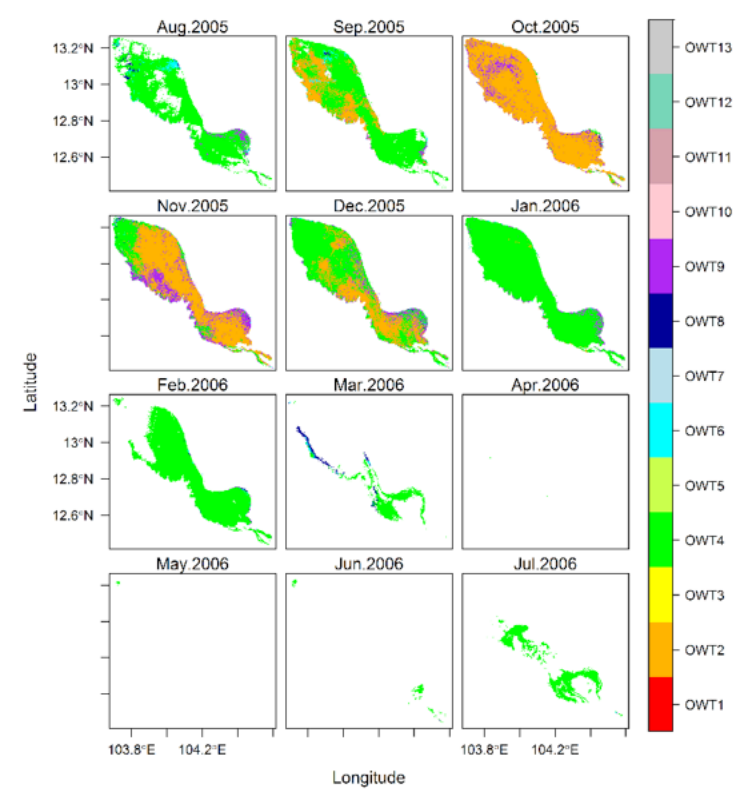

Figure 2. Dominant OWT over a yearly cycle in an ephemeral and highly dynamic freshwater body (Tonlé Sap) at the Cambodian floodplain.

Figure 2 shows changes of dominant OWT over a yearly cycle in an ephemeral and highly dynamic freshwater body (Tonlé Sap) at the Cambodian floodplain. It clearly demonstrates the 
high spatial and temporal variability in dominant OWT, which is most likely related to water flow direction in low (MarchJuly) and high water level (August-February). Of note is the shift of dominant OWT from 4 (turbid waters with high organic content) to 2 (marginal dominance of pigments and CDOM over inorganic suspended particles) at the highest water level (October, November) and the co-existence in some months of two or more OWT within the lake (OWT2, OWT4, OWT6, OWT8, OWT9). This variability would pose significant challenges in the retrieval of biogeochemical parameters from remote sensing data using a standard retrieval algorithm.

Previous research (Moore et al. 2014; Spyrakos et al. 2011) has shown that RS retrieval algorithms operating developed or/tuned for specific optical water conditions outperform algorithms developed or/and tuned operating in mixed compositions of optical properties water types over a large range of water constituents concentrations. This could be expected considering the dynamic range of conditions especially in inland and coastal environments. Testing and evaluation of an exhaustive list of algorithms over a wide range of conditions will be required to fully assess the potential of the developed framework for improvement of remote sensing products. This is shown in section 1.3.3

\subsubsection{Atmospheric correction (AC)}

The performance of AC model is particularly important for the retrieval of water properties by remote sensors especially when algorithms based on water-leaving reflectance are employed. For example inaccurate AC of signal in the retrieved Rrs spectra in the blue part of the electromagnetic spectrum will limit the utilization of these bands in models for retrieval of biogeochemical parameters.

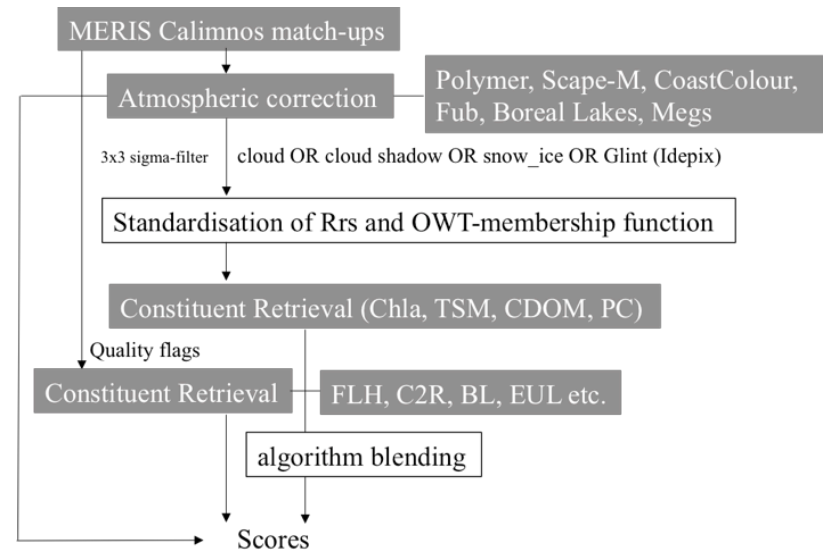

Figure 3. Flowchart of algorithm blending development and assessment.

Accurate AC is still considered a challenging task over nearshore and inland aquatic systems. Several methods have been developed for aerosol retrieval and atmospheric correction of EO data over these waters drifting away from classic algorithms for oceanic systems that assume negligible water-leaving radiance in the infrared. These methods can be generally distinguished to water-targeting and land-surface models depending on the assumptions for water spectra at the lower boundary (Tyler et al, 2016). While some AC schemes appear to be used more frequently in the literature, there are currently no standard models for AC of satellite data over inland and nearshore waters. The results of the NERC Globolakes project on the AC of MERIS data will be presented in this talk. Warren et al. (2019) identified the most suitable AC models for Sentinel-2 (S-2) over inland and coastal waters in Europe.

\subsubsection{Retrieval algorithms}

It is now widely known that standard Ocean Colour (OC) algorithms perform poorly in optically complex inland and coastal waters. There are many different retrieval algorithm architectures and parameterizations proposed for different lakes and coastal systems but it seems that their performance is very type-specific. There is actually a list of numerous retrieval algorithms, which will continue growing with increasing quantity, quality and availability of EO data, availability of insitu data and the expansion in the use of powerful inversion methods all aiming for more accurate retrieval. The general applicability of these approaches is subject to model benchmarking and the level of maturity

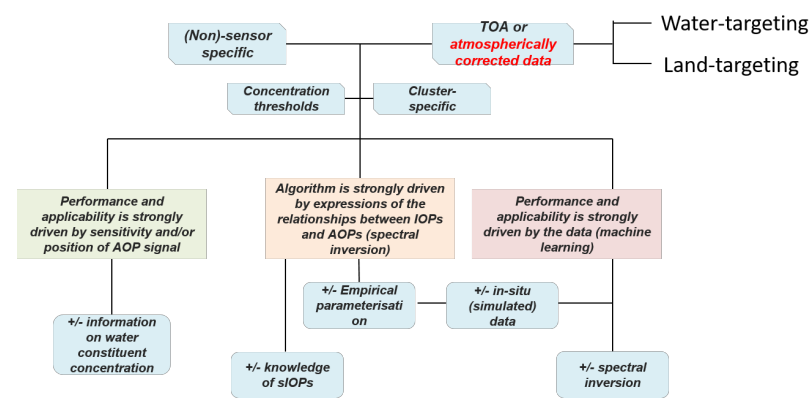

Figure 4. Overview of retrieval algorithms used in EO of inland and coastal waters

Our work overcame this challenge by developing a processing chain where algorithms are dynamically selected according to the optical properties of the water under observation (Neil et al, 2019) (Fig. 5). The development and validation of the GloboLakes processing chain has been supported by access to extensive in- situ data from more than thirty partners around the world that are now held in the LIMNADES community-owned database. This approach has resulted in a step-change in our ability to produce regional and global water quality products for optically-complex waters complete and a framework for delivering greatly improved uncertainty estimates.

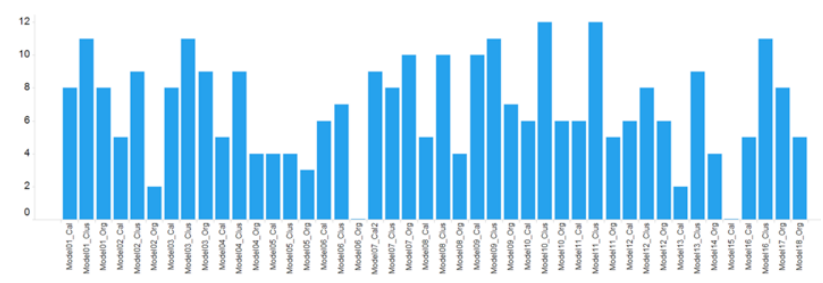

Figure 5. Benchmarking results of chlorophyll a algorithms.

\subsubsection{Calimnos processing chain}

Remote sensing of optical water quality, in particular biogeochemically, ecologically and economically relevant variables such as the standing stock of phytoplankton, has reached a level of maturity allowing initiatives such as the NERC-GloboLakes (www.globolakes.ac.uk), ESA-Diversity II (http://www.diversity2.info/) and ESA Ocean Colour CCI projects to map, optical water quality at larger scales and over long-term time-series. NERC-GloboLakes have developed the 
Calimnos satellite data processing chain that adapts to 13 optically distinct water types and corresponding retrieval algorithms for chlorophyll-a (proxy for phytoplankton biomass), phycoyanin (proxy for cyanobacteria), total suspended matter (turbidity, light climate), and dissolved organic substances (light climate, brownification, lake trophic function) (Fig. 5). A tenyear time-series of 1,000 lakes globally have been produced for GloboLakes to relate environmental change (catchment and climate drivers) to optical water quality. Calimnos has been used to operational Sentinel-3 OLCI data processing as part of an extension to the Copernicus Global Land Service.
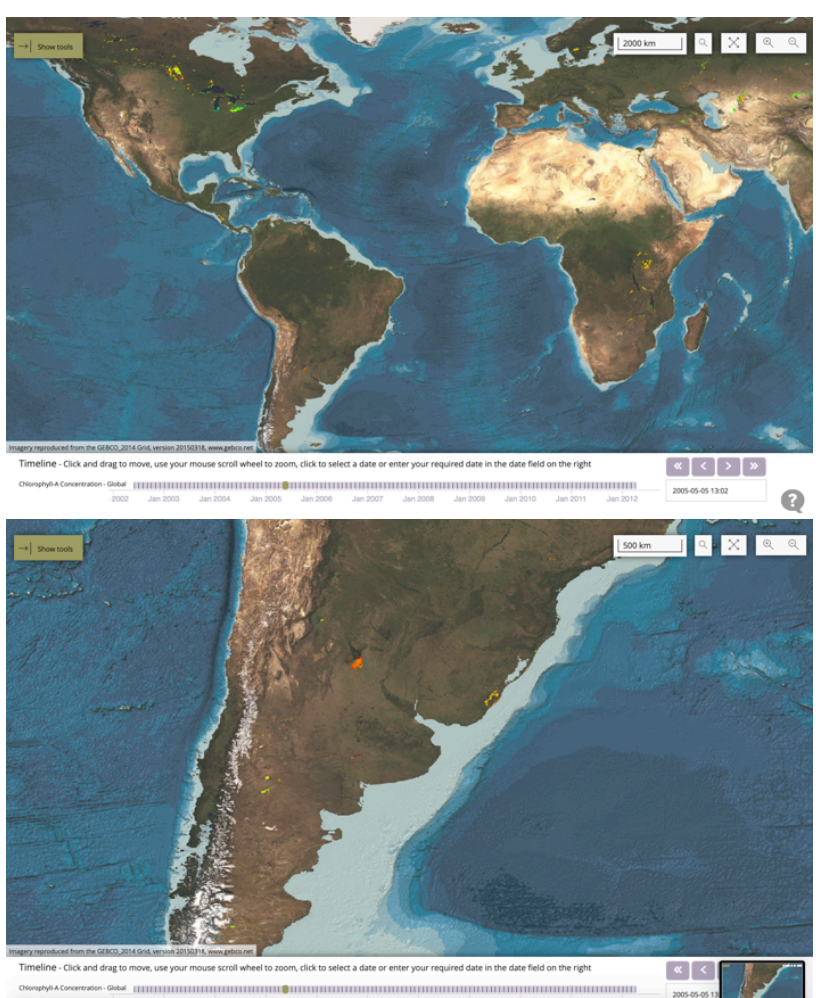

Figure 5. Snapshot of WebGIS platform developed by Plymouth Marine Laboratory for global water quality (https://globolakes.eofrom.space).

\subsection{Innovative and higher level products}

As part of the $\mathrm{H} 2020$ CoastObs project we are developing a range of data products for coastal waters from S-2 (MSI) and S3 (OLCI) data, including seagrass and macroalgae mapping, primary production (PP) (Fig. 6), phytoplankton size classes (PSCs) and the detection of HABs. We will present results from the intense biogeoptical characterisation and validation activities in Italy (Venice Lagoon), Spain (Ria de Vigo) and the Netherlands (Wadden Sea and Eastern Scheldt) during 2018 and 2019 and the development of these higher level products (mainly PP, PSC and HABs) from different sites in Europe.
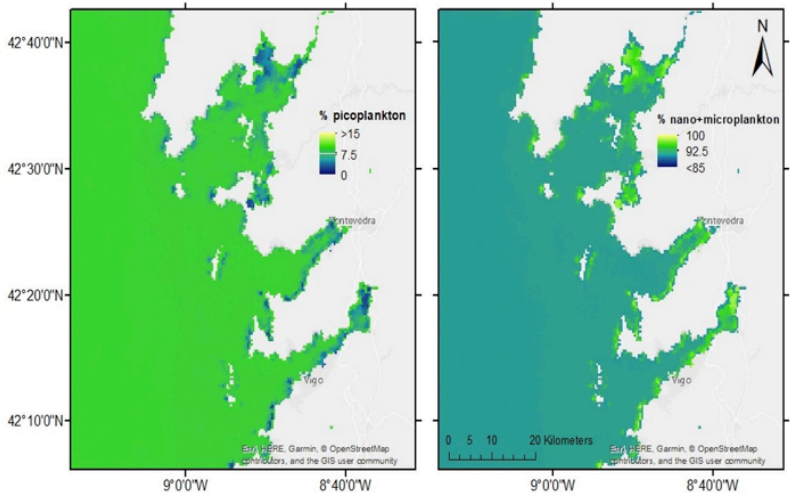

Figure 6. Example of PSC map over Galician rias based on S-3 images. C1 - picoplankton. C2,3 - nano- + microplankton.

\subsection{Remote Sensing of Harmful Algal Blooms (HABs) in Patagonia}

EO techniques now provide the opportunity to detect the temporal and spatial occurrence of eutrophic events providing new insights and mechanistic understanding of the influence glacier meltwater to HABs. Access to over twenty years of water colour remote sensing data (ESA's SeaWIFS and Envisat MERIS; NASA's MODIS and Landsat Program) coupled with the Sentinel 2 and 3 platforms provide the capability to hindcast disturbance events in the area and could be used to detect changes in bloom-forming organisms, bloom occurrences and eutrophication status.

The potential of RS for early detection and tracking of harmful algal events has been successfully demonstrated in a wide range of environments. Torres et al. (2019), for example, used MERIS data to study the occurrence of blooms in the NW of Spain; an area with an extensive mussel farming industry. Significantly, the launch of ESA S-2 and S-3 satellite offers a timely opportunity to further the development of operational satellitebased monitoring of coastal and inland waters, particularly as it will provide much improved coverage of the southern hemisphere.

However, remote sensing products are not always totally accurate in local areas and highly dynamic systems. Coastal waters in are normally characterised by considerable variability in the vertical distribution of phytoplankton and in their optical properties. Very little is yet known about the optical properties of this area.

As part of MEC80180058 and AUB 1900003 Conicyt projects, we characterised the bio-geo-optical properties of Patagonian coastal waters onboard the research vessel Cado de Hornos in November 2019. The main objective was to invistigate the relationships between glacier meltwater and HABs in nearglacier waters and adjucent coastal regions. With this campaign we expect firstly to gain a better understanding of space-time variability in the optical properties of the Southern Patagonian fjiords and secondly to provide suitable datasets for the testing and benchmarking of algorithms for current (at the time of the campaign) satellite-based sensors (Fig 7). Field data included above water Rrs, total spectral absorption and scattering, absorption of coloured dissolved organic material (CDOM) and phytoplankton and non-algal particles, optical particle scattering and backscattering. 


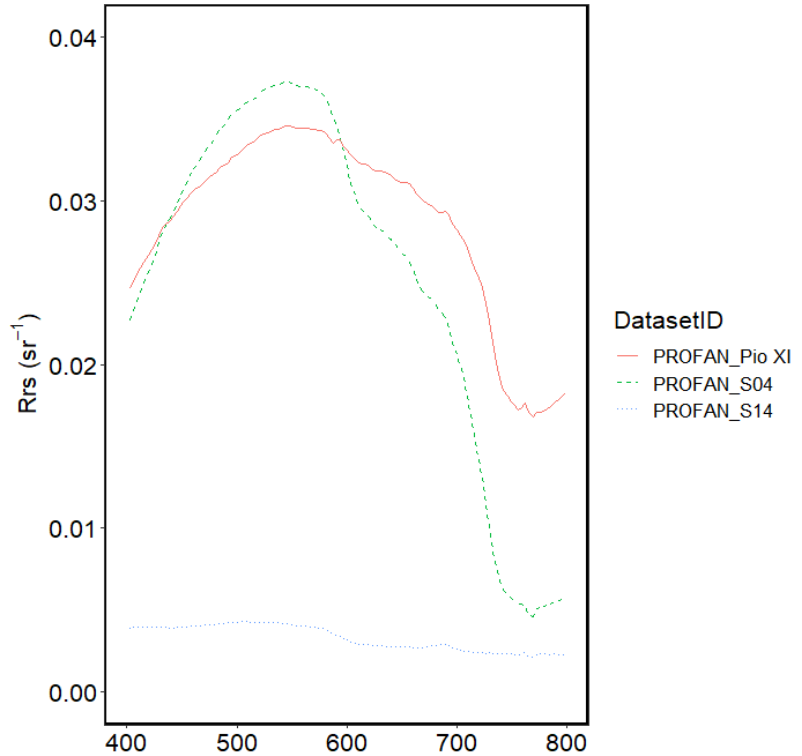

Figure 7. Remote sensing reflectance (Rrs) of 3 stations at different distances from glaciers as function of wavelength $(\mathrm{nm})$ collected during the PROFAN campaign in November 2019.

\section{Discussion and Concusions}

Our recent and on-going projects have delivered a step change in global scale observation of inland and near-shore waters. To develop a global understanding of how inland waters are responding to drivers of environmental change, the Stirling-led NERC GloboLakes project (2012-2018) (www.globolakes.ac.uk) pioneered in transforming the application of Earth Observation (EO) for lake condition monitoring from the local to the global scale. This achievment has been brought about by the global characterisation of optical water types. This was possible through the international collaboration of over 30 partners, whose data have contributed to the community owned data base LIMNADES, developed and managed by Stirling. GloboLakes has delivered the operational capability to monitor more than $50 \%$ of the world's inland surface waters (for waterbodies $>0.1 \mathrm{~km} 2$ in area) https://globolakes.eofrom.space/.

The H2020 CoastObs project led by Water Insight is developing service platform for coastal water monitoring with validated products derived from EO. In dialogue with users from various sectors, CoastObs has developed innovative EO-based products: monitoring of seagrass and macroalgae, algae as well as higher level products such as indicators and integration with predictive models.

At present water quality data are produced in three Copernicus services: Copernicus Marine, Copernicus Global Land and Copernicus Global Land. The approaches and methodologies to retrieve water-quality information differ between the services. The H2020 project Copernicus Evolution: Research for harmonised Transitional water Observation (CERTO) starting in 2020 is aiming to provide harmonised water quality products from the three relevant Copernicus services across a continuum of oceans, seas, coasts, estuaries, lagoons, rivers and lakes, to support industry, policy-makers and academia through research on harmonised water optical classification approaches.

This presentation aims to generate discussion on:

- Gaps in existing technologies and algorithms for operational product generation and validation at global scales (Availability and/or accessibility of in- situ data for algorithm calibration and validation? Processing capacity? Local knowledge?)

- Which accompanying measures should be undertaken in order to improve uptake of remotely sensed products for monitoring purpose, in developed as well as developing countries?

- Commercially sustainable services after the life-time of research projects and inter-operational/scalable services

- $\quad$ Desired specifications of EO sensors for monitoring complex waters

- How we can improve product consistency across data from multiple sensors?

- How do we fill information gaps (smaller water bodies, high cloud coverage)? Opportunities for developing low-cost solutions for citizen scientists

- What changes are needed to deal with complex atmospheres around inland and coastal waters?

- Need for new algorithms for specific water types (algorithm development).

- Is there demand for a continuum of water quality products (source to sink)?

- What water products do we need and how do these map onto existing and forthcoming capability (algorithm and platform)?

\section{ACKNOWLEDGEMENTS}

We would like to thank the European Union's Horizon 2020 research and innovation programme (CoastObs, grant agreement $\mathrm{n}^{\circ} 776348$, EOMORES, grant agreemnt no. 730066 and CERTO staring in January 2020), UK NERC-funded GloboLakes project (REF NE/J024279/1) and Conicyt projects MEC80180058 and AUB 1900003.

\section{REFERENCES}

Verpoorter, C., T. Kutser, D. A. Seekell, L. J. Tranvik, 2014: A global inventory of lakes based on high-resolution satellite imagery. Geophys. Res. Lett. 41, 6396-6402.

Spyrakos, E., ODonnell, R., Hunter, P., Miller, C., Scott, E.M., Simis, S., Neil, C., Barbosa, C., Binding, C., Bradt, S., Bresciani, M., DallOlmo, G., Giardino, C., Gitelson, A., Kutser, T., Li, L., Matsushita, B., Martinez-Vicente, V., Matthews, M., Ogashawara, I., Ruiz-Verdu, A., Schalles, J., Tebbs, E., Zhang, Y., Tyler, A., 2018. Optical types of inland and coastal waters. Limnology and Oceanography 63(2), 846-870.

Moore, T. S., M. D. Dowell, S. Bradt, Ruiz Verdu, A., 2014: An optical water type framework for selecting and blending retrievals from bio-optical algorithms in lakes and coastal waters. Remote Sensing of Environment 143, 97- 111.

Spyrakos, E., Gonzalez Vilas, L., Torres Palenzuela, J., Barton, D., 2011: Remote sensing chlorophyll a mapping of optically waters (rías Baixas, NW Spain): Application of a regionally specific chlorophyll a algorithm for MERIS full resolution data during an upwelling cycle. Remote Sensing of Environment 115(10), 2471-2485.

Tyler, A., Hunter, P., Spyrakos, E., Groom, S., Constantinescu, A., Kitchen, J., 2016: Developments in Earth observation for the assessment and monitoring of inland, transitional, coastal and shelf-sea waters. Science of the Total Environment 572, $1307-1321$. 
Warren, M.A., Simis, S.G.H., Martinez-Vicente, V., Poser, K., Bresciani, M., Alikas, K., Spyrakos, E., Giardino, C., Ansper, A., 2019: Assessment of atmospheric correction algorithms for the Sentinel-2A MultiSpectral Imager over coastal and inland waters. Remote Sensing of Environment 225, 267-289.

Neil, C., Spyrakos, E., Hunter, P.D., Tyler A.N., 2019: A global approach for chlorophyll-a retrieval across optically complex inland waters based on optical water types. Remote Sensing of Environment 229. 159-178.

Torres Palenzuela, J., Gonzalez Vilas, L., Bellas Alaez, F., Garet, E., Gonzalez Fernadez, A., Spyrakos, E., 2019. Pseudonitzschia blooms in a coastal upwelling system: Remote Sensing detection, toxicity and environmental drivers. Water 1(9), 1954. 